\title{
Dynamic accounting of greenhouse gas emissions from cascading utilisation of wood waste
}

\section{Faraca, Giorgia; Tonini, Davide; Astrup, Thomas Fruergaard}

\section{Published in:}

Science of the Total Environment

Link to article, DOI:

10.1016/j.scitotenv.2018.10.136

Publication date:

2019

Document Version

Peer reviewed version

Link back to DTU Orbit

\section{Citation (APA):}

Faraca, G., Tonini, D., \& Astrup, T. F. (2019). Dynamic accounting of greenhouse gas emissions from cascading utilisation of wood waste. Science of the Total Environment, 651(Part 2), 2689-2700.

https://doi.org/10.1016/j.scitotenv.2018.10.136

\section{General rights}

Copyright and moral rights for the publications made accessible in the public portal are retained by the authors and/or other copyright owners and it is a condition of accessing publications that users recognise and abide by the legal requirements associated with these rights.

- Users may download and print one copy of any publication from the public portal for the purpose of private study or research.

- You may not further distribute the material or use it for any profit-making activity or commercial gain

- You may freely distribute the URL identifying the publication in the public portal 
3 Dynamic accounting of greenhouse gas emissions from cascading utilisation of wood waste

5

6

8

9

10 11

12 13

14

15

16

17

18

19

20 4 5 6 7 8 9
Giorgia Faraca* ${ }^{l}$, Davide Tonini ${ }^{2}$, Thomas F. Astrup ${ }^{l}$

${ }^{1}$ Department of Environmental Engineering, Technical University of Denmark, Miljфvej. Building 115, 2800 Kgs. Lyngby, Denmark

${ }^{2}$ European Commission, Joint Research Centre, Edificio Expo, Calle Inca Garcilaso 3, 41092 Seville, Spain

*) Corresponding author: gfar@env.dtu.dk 


\section{Abstract}

Cascading utilisation of post-consumer wood waste has recently gained increasing attention in the European Union, aiming for a society in which the resource's properties are optimised through sequential uses. To date, material utilisation of wood waste has been limited to particleboard production, with additional niche alternatives being restricted by quality requirements for wood waste. In this consequential life cycle assessment focusing on post-consumer wood collected at Danish recycling centres, Global Warming Potential (GWP) impacts from quality-driven choices for cascading management of wood waste were compared with those from handling mixed wood waste qualities. GWPs were modelled by considering the dynamic profile of greenhouse gas emissions (including biogenic carbon dioxide) for two time horizons (100 and 500 years). The robustness of the results was tested by varying modelling assumptions with respect to electricity system, wood sourcing and associated rotation period, and impacts from indirect land use changes. The results demonstrated that valuing quality over quantity in wood waste management can ensure larger GWP savings, especially if recycling applications have a long lifetime and/or substitute energy-intensive products; such results were confirmed under all scenario analyses. Inclusion of land use changes credited land-intensive products. More cascade steps of the wood waste resource ensured larger savings; however, assumptions on the electricity mix, on the source of the wood alongside the choice of the time horizon for GWP greatly influenced the results on cascading management.

Keywords: wood waste, time-dependency, Global Warming Potential (GWP), dynamic life cycle assessment (LCA), quality, resource cascading

\section{Introduction}

Wood waste is a versatile resource that can be used for both material and energy production. In 2007, $52 \%$ of the 36 million $\mathrm{m}^{3}$ of post-consumer wood waste recovered in the European Union (EU) was redirected to material use (Leek, 2010), with the rest being sent to the energy sector. By 2030, wood waste is expected to 
contribute with 59-67 million $\mathrm{m}^{3}$ to annual EU wood demand (Mantau et al., 2010). However, increasing demand for this constrained resource and the presence of policy targets simultaneously encouraging recycling (e.g. circular economy) and energy recovery (e.g. Renewable Energy Directives) may generate competition of uses between sectors, potentially incurring suboptimal environmental performances. In this respect environmental assessments, performed to support policies and decisions, have often delivered contradictory results: some life cycle assessment (LCA) studies indicate that wood waste management via recycling is environmentally favourable over incineration (e.g. Bais-Moleman et al., 2018; Borjesson and Gustavsson, 2000; Rivela et al., 2006a), although differences are not substantial. By contrast, Werner et al. (2010) conclude that thermal treatment is preferable to recycling because it minimises the risk of dispersing pollutants contained in the waste. Morris (1996) and Dodoo (2009) also indicate energy use as the preferable option.

The circular economy adopted by the EU favours a "resource cascading" approach (Sirkin and Houten, 1994), aiming for a society in which resource utilisation is optimized through sequential uses. This approach involves two dimensions, namely quality and time: to extend the entire lifetime of the material, its properties are subsequently used in different applications according to its quality grade (Fraanje et al., 1998). Wood waste utilisation can be cascaded in time or in value: when cascaded in time, wood waste is remanufactured to the same type of product in an iterative way, as many times as its quality permits. When cascaded in value, wood waste is recycled into different product applications as its quality declines; therefore, early choices in the resource lifecycle will more or less restrict future recycling applications and increase the overall lifetime of the material. In resource cascading recycling and energy recovery may coexist, as the wood waste that is recycled today will be combusted at the end of its lifetime (when its functions/properties have been fully exploited). "Longer" cascades do not necessarily lead to larger environmental savings but only refer to the potential of extending the overall lifetime of the resource: Dornburg and Faaij (2005), using carbon accounting, showed that longer cascades increase or decrease net $\mathrm{CO}_{2}$ emissions per hectare of biomass production depending on the net $\mathrm{CO}_{2}$ emissions of the respective application.

Post-consumer wood waste in the Nordic countries is mainly collected at recycling centres, which are manned collection points where private citizens deliver their waste (Krook and Eklund, 2010). Currently, material utilisation of so collected post-consumer wood waste is absorbed almost entirely into the production 
of particleboard (European production was 34.8 million $\mathrm{m}^{3}$ in 2015; FAO/UNECE, 2016). This type of woodbased panel is made by chipping wood and pressing it into a mat with the addition of resins. Due to the simplicity of the manufacturing process, particleboard production can accommodate a large amount of postconsumer wood waste - up to $100 \%$ of the wood content depending on the country (in Denmark, it represents 80\%; Vis et al., 2016). No wood waste inputs are typically expected in the recycling of paper, as it is considered an almost closed-loop sector (Höglemeier et al., 2015), but additional options for wood waste include solid wood applications (e.g. floor boards), cellulosic insulation materials, wood composites and bio-chemicals, albeit representing niche markets linked closely to the quality of the feedstock. According to the German legislation (Altholz V, 2012), post-consumer wood waste can be classified into four quality grades (Q1 to Q4) of which the two upper grades (Q1 and Q2) are suitable for recycling, the third grade (treated wood and woodbased panels, Q3) for incineration and the last (Q4) for disposal of as a hazardous material, due to being impregnated with preservatives (see Table B.1 in Appendix B). In Denmark, particleboard production may also accept input of Q3 wood waste as long as not exceeding thresholds for selected chemical elements. The possibility of unlocking other wood waste recycling applications via a quality distinction of the feedstock has not been explored to date.

Cascading utilisation of wood/wood waste has recently received increasing attention. With respect to existing LCA studies on the topic, Dornburg and Faaij (2005) demonstrated the potential for $\mathrm{CO}_{2}$ mitigation of several cascading chain possibilities for short-rotation poplar. Sikkema et al. (2013) compared cascade chains for forest resources in Canada in terms of climate mitigation, suggesting that harvested wood should be used first for sawn wood, then for wood-based panels and finally energy recovery in order to decrease greenhouse gas (GHG) emissions. Bais-Moleman et al. (2017) demonstrated via environmental optimisation of EU forest sector utilisation that wood product cascading increases the efficiency of the resource use in general, but it can be less favourable in terms of GHG emission reduction in case it would divert the feedstock from the energy sector, that may compensate by using fossil fuels or virgin wood. With respect to wood waste, three studies (Höglemeier et al., 2014; Risse et al., 2017; Suter et al., 2016) assessed the impacts of its cascading utilisation via particleboard recycling in Germany and Switzerland, concluding that wood waste recycling can generate fewer environmental impacts than primary wood systems, although savings in Global 
Warming Potential (GWP) decrease in line with additional cascade steps. Finally, Mehr et al. (2018) through

100 material flow analysis, LCA and optimisation modelling identified reduced GWP impacts from cascading

101 Swiss wood resources. A review by Thonemann and Schumann (2018) concluded that the environmental soundness of wood cascading has yet to be proved. While comparing cascading of wood products to primary wood production systems, the abovementioned studies have not addressed how quality-driven choices for wood waste management may potentially affect the GWP performance of the system. This implies selective collection/handling and recycling favouring quality in place of quantity. An assessment of potential savings from cascading possibilities of upper qualities wood waste compared to handling mixed wood waste is missing in the literature. Studies on cascading of post-consumer wood waste from recycling centres are also missing. LCA studies of biomass systems especially discuss impacts in terms of the indicator GWP, because wood resources are essentially made of biogenic carbon, therefore potentially providing climate change mitigation by displacing fossil fuels through energy recovery and carbon storage through material substitution, in addition to substituting other non-renewable materials which are usually manufactured through carbonintensive processes, such as steel and concrete. However, two fundamental aspects related to GWP accounting appear to have been largely overlooked. First, emissions of biogenic $\mathrm{CO}_{2}$ from wood (waste) combustion are not accounted for, because they are assumed to be re-sequestered as new plantations grow. The consequence is that emissions of carbon dioxide following biomass combustion are implicitly considered neutral. However, recent publications (e.g. Cherubini et al., 2011; EC, 2016a; Guest et al., 2013) have demonstrated that wood combustion should not be considered carbon-neutral when constituted by biomass species with a rotation period of several decades, therefore questioning conclusions obtained under a carbon neutrality assumption.

119 The second limitation is the lack of temporal information: emissions occurring during the life cycle are modelled as an aggregated value irrespective of the time at which they occur. This equates to considering all emissions as if occurring at year zero and then summing them up over the selected time horizon. A dynamic profile of the emissions is rarely considered, despite De Rosa et al. (2017) and Levasseur et al. (2010, 2013) demonstrated that neglecting such emissions occurring late in the time horizon of the scenarios may lead to biased interpretation. A review by Røyne et al. (2016) found that $97 \%$ of 101 articles on wood or forest systems 
emissions. None of the aforementioned cascading wood studies considered timing of GHG emissions, and only Mehr et al. (2018) included biogenic $\mathrm{CO}_{2}$ impacts, albeit through a simplified approach.

Acknowledging these shortcomings of existing LCA literature on wood waste management and in the attempt of advancing the knowledge of the associated environmental impacts, the aim of this study is two-fold: i) to systematically assess the GWP of alternative wood waste cascading systems - we do this by considering an emission profile for each scenario and by performing a dynamic accounting where the GWP of biogenic carbon emissions is assessed building on state-of-the-art approaches; ii) to highlight and discuss the role played by the quality of wood waste with respect to the potential climate change mitigation benefits - we do this by comparing recycling options for mixed wood waste qualities versus the case in which the different qualities are handled separately and follow appropriate management routes. We illustrate the results under different scenario assumptions with respect to time horizon, electricity system, wood sourcing and associated rotation periods, and indirect land use change impact. The focus of the study is on Danish wood waste from recycling centres.

\section{Materials and methods}

\subsection{Goal, scope and functional unit}

The goal is to assess the GWP (IPCC 2013) of alternative scenarios for post-consumer wood waste management and to compare them against current practice. The functional unit (FU) adopted in the modelling is the management of 1 tonne of post-consumer wood waste collected at Danish recycling centres. Postconsumer wood waste is not a homogenous material but it does consist of a variety of items differing in source, type and quality (Faraca et al., 2017) and can be contaminated by presence of wood impregnated with preservatives and other material fractions. Following the German legislation (Altholz V, 2012), the quality composition of the wood waste in this study is $4 \% \mathrm{Q} 1,56 \% \mathrm{Q} 2,32 \% \mathrm{Q} 3$ and $6 \% \mathrm{Q} 4$, the rest being other material fractions (impurities; see Table S1 in SI). Wood waste of grades Q1, Q2 and Q3 is generally collected in a single container at Danish recycling centres, whereas grade Q4 follows other disposal routes (landfill or incineration in special plants) and its presence was accounted for as impurity. The geographical scope is 
152 Denmark; technology efficiencies/emissions are assumed to be in line with 2015-2030 expected performances.

153 For the temporal profile of emissions, we assume 2015 as the starting year of the assessment. The study follows

154 a consequential approach, as it intends to model the consequences in terms of GWP of implementing a portfolio

155 of wood waste management schemes. Considering that wood waste represents a minor amount compared to

156 the wood traded for goods and energy (see Annex 5 of Gurria et al., 2017), it is assumed that the changes

157 induced by such waste management schemes do not affect the determining parameters of the overall market

158 situation (direction of the trend in market volume and the constraints on and production costs of the involved

159 products/technologies; see also Weidema et al., 2009).

160

\subsection{System boundaries and scenarios definition}

The system boundary (Figure 1) starts after the collection phase and ends at the point where the waste loses its functional properties and can no longer be recycled, but only disposed of through incineration or landfilling. Two sets of scenarios were developed, based on whether or not the collection (and the management of wood waste) reflected the quality distinction of the material: I) four "Wood Waste, mixed qualities" scenarios (WWmix, A1 to A4; the four scenarios represent the possibility to perform up to four particleboard cascades), where wood waste is collected following current practice (one container for Q1+Q2+Q3 which is sent to particleboard production; Q4 is present as impurity); and II) eleven "Wood Waste, quality distinction" (WWquality, B1 to F1) scenarios, where the distinction in quality classes is in place through separate collection (one container for $\mathrm{Q} 1+\mathrm{Q} 2$, which is sent to recycling, and one for $\mathrm{Q} 3$, which is sent to incineration; $\mathrm{Q} 4$ is assumed to be collected in a container for impregnated wood and sent to incineration at special plants). In WWquality scenarios alternative recycling options for Q1+Q2 were tested, while Q3 and Q4 were always assumed to be incinerated in municipal solid waste incinerators (MSWI) and special plants, respectively (typical fate in Denmark); thus, their management does not differ across scenarios. All in all, we considered the following possible recycling applications of the collected post-consumer wood waste: 
formaldehyde resin before being hot-pressed into a mat. Wood waste constitutes $80 \%$ ww of the feedstock for particleboard in Denmark (Vis et al., 2016), while urea-formaldehyde resin constitutes typically $10 \%$ ww of the final product (Wilson, 2010; Rivela et al., 2006b).

- Production of floor boards. Wood waste of usable dimensions is manually made impurity-free, sawn to 2.5 $\mathrm{cm}$ thickness and planed.

- Production of wood insulation board (WIB). Wood waste is processed into chips, heated and fed to a defibration process. The fibres are dried in a cyclone and mixed with $1.3 \%$ ww bi-component fibres (polyethylene or polypropylene) and 3.6\% ww adhesives and fire retardants (González-García et al., 2009; Steico, 2016).

- Production of wood plastic composites (WPCs). The wood waste is shredded, dried, and grinded until producing < $1 \mathrm{~mm}$ particles with $10 \% \mathrm{mc}$. The wood particles are blended with plastic granules (HDPE assumed from secondary materials) at a 1:1 ratio and a coupling agent and compounded at $170{ }^{\circ} \mathrm{C}$. The last step is compression moulding (Bolin and Smith, 2011; Sommerhuber et al., 2017).

- Production of pellets. Although this scenario is typically performed on industrial residues or Q1 wood waste, it was assumed possible also for Q2, as previous studies have confirmed that chemical composition of wood residues of Q1 and Q2 is comparable (Faraca et al., 2017). Wood waste undergoes shredding and grinding before drying until $8-10 \% \mathrm{mc}$ and pelletising. The product is burnt in a combined heat and power (CHP) plant. Any wooden by-products originating from the wood waste reprocessing stage were assumed to be combusted in small-size biomass boilers provided with heat recovery. Foreign materials found in the collected wood waste were assumed to be separated at collection points and sent for recycling (ferrous and non-ferrous metal impurities), landfilled (glass, stones, composite building materials), and incinerators provided with electricity and heat recovery (plastics, textiles, cardboard, garden waste). Fly and bottom ashes originating from the combustion and incineration processes were assumed to be disposed of in dedicated landfills for fly and bottom ash, respectively. 


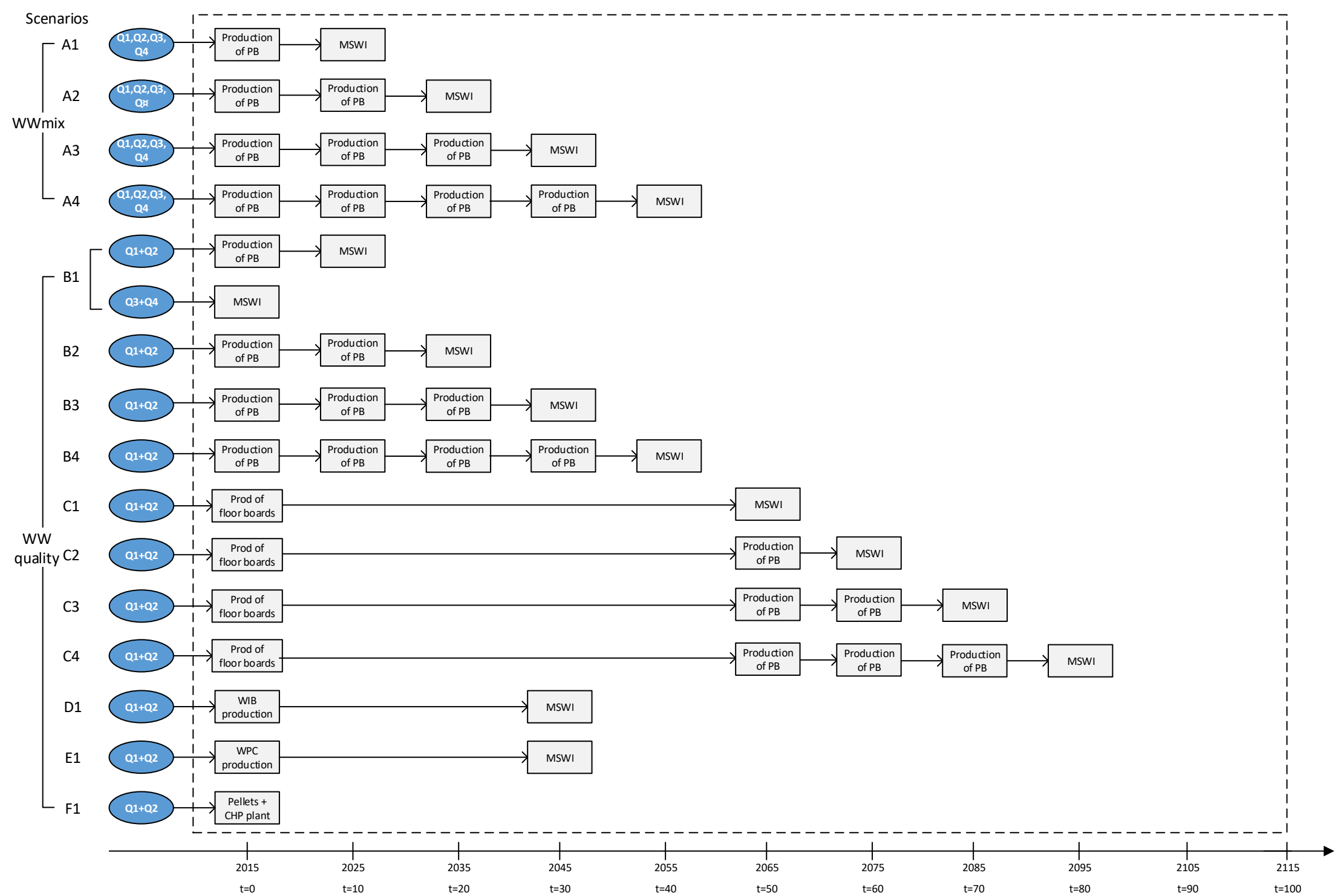

203 Figure 1. Schematic system boundaries of the scenarios under assessment. PB = particleboard; MSWI = municipal solid waste incinerator; WIB = wood insulation boards; WPC = wood 204 plastic composites. In WWquality scenarios the management of Q3 and Q4 is maintained constant as depicted exemplarily for scenario B1: Q3 is incinerated in MSWI, Q4 is incinerated 


\subsection{Identification of marginal processes and technologies}

Any additional product generated during the management of the wood waste was credited with the substitution of corresponding market products, applying system expansion as common practice in waste LCAs and recommended by ISO (2006). Following consequential LCA principles, this implies identifying the marginal suppliers (Weidema et al., 2009). For the provision of electricity, the marginal source for Denmark was assumed to consist of 61\% wind energy and 39\% biomass-energy (in the form of wood pellets) conforming to the figures provided by Munõz et al. (2015) and EC (2016b). Heat was assumed to be produced from natural gas-based boilers, this being the most likely thermal energy source for individual producers (in the absence of a connection to district heating). The marginal product for insulation was identified in glass wool, on the basis of the information reported in Kalt et al. (2016). With respect to the marginal source of the wood, it should be noticed that, along with post-consumer wood waste to be managed, two additional wood biomasses were involved in the assessment: the virgin wood products whose provision and manufacture is avoided through wood waste recycling (scenario A1 to C4 and E1; see Figure 1 and Appendix C), and wood pellets constituting a share of the marginal mix for electricity supply (39\% of the total) and also representing one of the wood waste recycling applications (scenario F1; see Figure 1). Currently, wood for particleboard, WPC, and pellets identified two sourcing alternatives: I) forest wood from surrounding countries with large resource availability (Latvia, Sweden, and Russia), typically having a rotation time between 40 and 100 years; for this, we assume a rotation time of 60 years for use in the baseline calculations. II) short-rotation plantations, exemplified by Brazilian eucalyptus forest, being suggested as a likely future source in previous studies (Schmidt and Brandao, 2013; Thrän et al., 2017); for this, we assume a rotation time of 10 years as an alternative to the baseline assumptions (see Section 2.6.3). While the first case reflects the current trend for wood sourcing and imports to Denmark, the second represents a possible future evolution of the market. 


\subsubsection{Dynamic accounting}

The dynamic accounting was facilitated by MATLAB and followed the mathematical approach described in Cherubini et al. $(2013,2015)$ and Levasseur et al. (2010): each activity in the inventory is assigned the year in which the emission takes place. For example, the activity "production of particleboard" in scenario $\mathrm{C} 2$ occurs at year 50. When a GHG is emitted to the atmosphere it degrades according to a GHG-specific atmospheric decay curve (the impulse response function, IRF). Therefore, at each year, the quantity of a GHG emitted by the system is multiplied by the atmospheric decay curve of a unit pulse emission of the GHG under assessment (see Figure 2). IRFs for $\mathrm{CO}_{2}$ are described in Section 2.2.2; IRFs for other GHGs were retrieved from Levasseur et al. (2010). The yearly curves are summed up to a total curve. The integral over time of the total curve divided by the integral over time of a unit pulse emission of $\mathrm{CO}_{2}$ emitted at year 0 (often referred to as the absolute global warming potential, $\left.\mathrm{AGWP}_{\mathrm{CO} 2}\right)$ represents the $\mathrm{GWP}\left(\mathrm{kg} \mathrm{CO}_{2}-\mathrm{eq} / \mathrm{FU}\right)$ for that system. This methodology could equally be carried out by calculating dynamic characterisation factors (dCF), which are obtained by calculating the integral over time of the atmospheric decay curve of a unit pulse emission emitted at year $\mathrm{t}$ divided by the integral over time of the decay emission of a unit pulse emission of $\mathrm{CO}_{2}$ emitted at year 0 . Yearly dCFs are then multiplied by yearly emissions; the products are summed and represent the GWP (see also Appendix E.5).

Since (biogenic and fossil) $\mathrm{CO}_{2}$ emissions in biomass systems account for the majority of total GHG emissions, other air emissions with a warming effect were modelled separately (Section 2.4.3), also given their temporary behaviour in the atmosphere compared to the persistency of $\mathrm{CO}_{2}$ (IPCC, 2013). Notice that the dynamic profile of emissions was applied both to the foreground and the background system. However, with respect to the latter, we did not assume a dynamic development of the energy (e.g. for electricity, heat, and transport fuels) supply mix over time, i.e. these were maintained constant over the years. This was done to isolate and highlight the effects related to the management of the wood waste per se and to reduce the number 
of variables in the system. The overall analysis was then carried out using the LCA-model EASETECH 258 (Clavreul et al. 2014).

\subsubsection{Fossil and biogenic carbon accounting}

The behaviour of $\mathrm{CO}_{2}$ in the atmosphere is the same irrespectively of the origin of the $\mathrm{CO}_{2}$ (biogenic or fossil), but the accounting depends on the carbon pools considered for the C cycle model (Cherubini et al., 2011). According to IPCC (2013), the Bern carbon cycle 2.5CC (Forster et al., 2007) was used for the dynamic accounting of fossil and biogenic $\mathrm{CO}_{2}$, as it considers the interaction of all compartments in the ecosphere. In the case of fossil $\mathrm{CO}_{2}$ emissions, Eq. 1 was used to calculate the IRF:

$$
f(t)=y_{C O 2}(t)=A_{0}+\sum_{i=1}^{i=n} A_{i} e^{\left(-\frac{t}{\tau_{i}}\right)} \quad n=1,2,3
$$

where $f(t)$ is the impulse response function (IRF) after the emission (i.e. the atmospheric decay, IRF of $\mathrm{CO}_{2}$ fossil) and $\mathrm{A}_{\mathrm{i}}$ and $\tau_{\mathrm{i}}$ are coefficients (see Appendix D)

In the case of biogenic $\mathrm{CO}_{2}$, Eq. 2 was used to calculate the IRF (based on Cherubini et al., 2011, 2013, 2016):

$$
f(t)=y(t)-\int_{0}^{T H} g(t) y(T H-t) d t
$$

where $\mathrm{f}(\mathrm{t})\left(\mathrm{IRF}\right.$ of $\mathrm{CO}_{2}$ bio) is obtained by the convolution of the $\mathrm{CO}_{2}$ emissions $\mathrm{y}(\mathrm{t})$ released at time $\mathrm{t}$ and the $\mathrm{CO}_{2}$ sequestered by the biomass regrowth $\mathrm{g}(\mathrm{t})$ in the period from $\mathrm{t}$ to $\mathrm{TH}$. The sequestration function $\mathrm{g}(\mathrm{t})$ depends on the rotation period of the wood species in question, as detailed in Cherubini et al. (2011) (see appendix D). Conformingly with the latter, we modelled biomass regrowth in the forest as a normal (Gaussian) distribution.

As the cascading utilisation of wood waste involves preserving the material properties (hence $\mathrm{C}$ content) for a certain period, the storage of biogenic carbon in the anthroposphere can be included in the IRF of $\mathrm{CO}_{2}$ 


$$
f(t)=\left\{\begin{array}{c}
f 1(t)=\int_{0}^{\tau} g(t) y(T H-t) d t, 0 \leq t<\tau \\
f 2(t)=y(T H-t)-\int_{\tau}^{T H} g(t) y(T H-t) d t, t \geq \tau
\end{array} \quad \text { Eq. } 3\right.
$$

where $\tau$ is the time period during which the wood waste in the FU is kept in the anthroposphere, i.e. the time at which the wood waste can no longer be recycled and is incinerated; it varies across scenarios depending on the lifetime of the recycled product and the number of cascades of the FU. assessment (Eq. 4):

where $\alpha$ is the radiative efficiency of $\mathrm{CO}_{2}$ and $\mathrm{C}_{0}$ is the unit pulse emission. For further details refer to Cherubini et al. (2011), Levasseur et al. (2010), Guest et al. (2012) and Appendix D.

The modelling considered a time horizon (TH) for the integration of the $\mathrm{CO}_{2}$ emissions equal to 100 years, i.e. for the period 2015-2114 (2114 is the last year) and to 500 years (2015-2514).

\subsection{Life Cycle Inventory}

Inventory data were retrieved from a number of publications and reports available in the literature. All data were taken into account by defining parameter distributions (see Section 2.6.1) which can be found in Section S6.2 of SI. Data for the particleboard production process was retrieved mainly from Merrild and Christensen (2009), Rivela et al. (2006b) and Wilson (2010). The main difference in modelling subsequent iterations of particleboard production was that half of the feedstock in input is lost at every recycling step, due to the dimensions of the chips and the presence of resin that may cause problems during shredding (Vis et al., 2016). Separation of qualities in scenarios B1-B4 led to higher technical yield (100\% instead of 94\%) and substitution factor ( 1 instead of 0.6 ) of the first iteration of particleboard production compared to scenarios 
particleboard production from virgin sources was modelled with the same data, the main difference being a 305 higher technical yield and a higher wood feedstock moisture content. The complete list of processes used in the modelling can be found in Appendix E.

According to Section 2.4, we calculated emission profiles for biogenic and fossil $\mathrm{CO}_{2}$ for each individual scenario investigated. While the detailed emission inventory may be found in Appendix E.5 (along with corresponding dCFs), Figure 2 illustrates the emission profile of biogenic and fossil $\mathrm{CO}_{2}$ for the case of scenario B1 as an example.
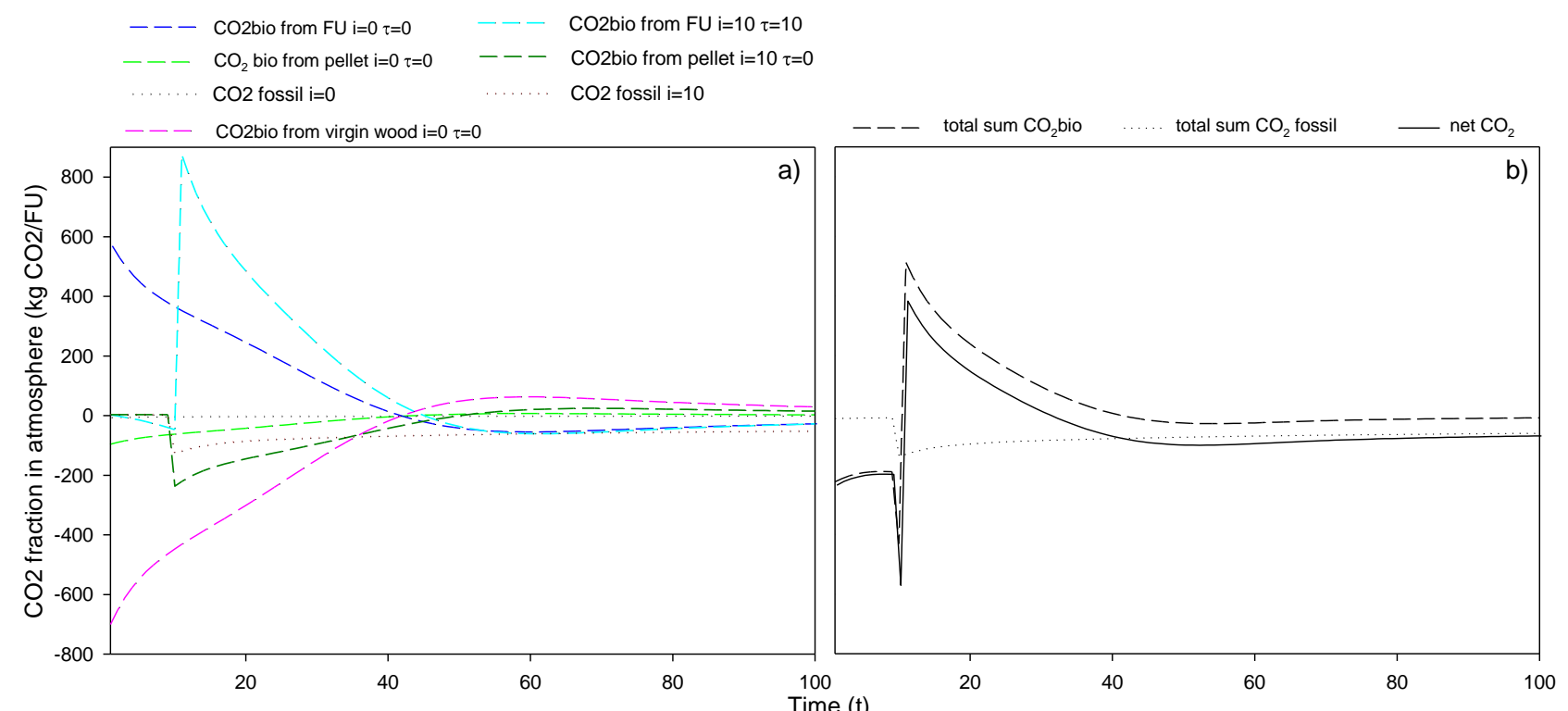

313 Figure 2. Time-dependent $\mathrm{CO}_{2}$ decay curves in the atmosphere illustrated exemplarily for scenario B1; (a) and 314 (b) graphs differ in the level of information aggregation. The curves in (a) represent different behavioural curves $\mathrm{f}_{\mathrm{i}}(\mathrm{t})$, as described in Section 2.4.2; the black solid curve in (b) represents $\mathrm{F}(\mathrm{t})$. $\mathrm{FU}=$ functional unit; $\mathrm{i}=$ year at which the emission occurs; $\tau=$ storage time.

\subsection{Uncertainty, sensitivity and scenario analysis}

\subsubsection{Combined sensitivity and uncertainty analysis}

Following the approach suggested by Bisinella et al. (2017), uncertainty on the foreground system (the waste management activities) was tested by thorough uncertainty propagation and sensitivity analysis. For the 
uncertainty propagation it was necessary to define LCI data as probability distributions. Due to the diversity of the information available in the literature, triangular distributions of the type (min,max,mode) were assumed. When the mode could not be calculated, the median was used instead (Tables E.18 and E.19 in Appendix E). The mode/median represented the baseline value while the entire distribution was used for the uncertainty propagation, which consisted of propagating the uncertainties associated with each input parameter to calculate the uncertainty associated with the results, covering the possibility of accumulative effects due to values (Bisinella et al., 2016).

\subsubsection{Scenario analysis II - Testing assumptions on wood sourcing and rotation}

Regarding the source of wood, the baseline assumption whereby wood is sourced from Nordic countries (rotation time 60 years, see Section 2.1.2) was supplemented by an import scenario in which Eucalyptus wood is supplied from Brazil (rotation time 10 years). In addition, given the uncertainty associated with the choice of the rotation period of the wood, results were also calculated for ten rotation times between 10 and 100 years (i.e. every ten years), to cover a wider span of possibilities. 


\subsubsection{Scenario analysis III - Inclusion of ILUC and other GHGs}

From a consequential modelling perspective, growing wood plantations incurs demand (and further occupation) for land. According to Schmidt et al.(2015), this implies the existence of a market for managed forest land, responsible for a share of the global land use change (LUC) $\mathrm{CO}_{2}$ emissions from deforestation; the rest being attributed to cropping and pasture, i.e. mainly agriculture. This impact is typically called indirect LUC (iLUC) as it represents the upstream consequences (transformation of land somewhere else, even beyond the assessed geographic system) of demanding the land, regardless of its final use. Avoiding (e.g. with increased recycling and displacement of virgin material) an additional demand for wood products should then be credited with the corresponding iLUC $\mathrm{CO}_{2}$ impact avoidance. In this study, the approach presented by Schmidt et al. (2015) was followed. The model assumes that the land use impacts from growing a forest depend on the amount of land demanded and the type and share of expansion on virgin nature taking place (transformation), assuming full-elasticity of supply (i.e. short-term effects due to price fluctuations are not included). Unlike crops, when wood residues are removed, no additional mineral fertiliser is assumed to be used to counterbalance the nutrient content of the removed wood residues (Schmidt et al., 2015). To illustrate the potential contribution from iLUC impacts we used a value of $0.32 \mathrm{~kg} \mathrm{CO} / \mathrm{kg}$ wood for long-rotation Latvian wood and of $0.05 \mathrm{~kg} \mathrm{CO}_{2} / \mathrm{kg}$ wood for short-rotation eucalyptus in Brazil (both derived after Schmidt and Brandão, 2012). Note that these figures have also been applied in a recent study by Vadenbo et al. (2017). To single out the importance of these effects, iLUC contribution will be reported and discussed separately. Similarly, the contribution from other GHGs will be kept separate from $\mathrm{CO}_{2}$ (see Section 2.2.1) and shown as additional scenario analysis.

\section{Results and discussion}

\subsection{Contribution to Global Warming Potential}

The characterised GWP results are shown in Figure 3 (rotation time 60 years). Figures below zero represent savings, while above zero burdens; we name the sum of savings and burdens "impact/net savings". 
Overall, all scenarios provided savings except for scenario F1 (pellet-CHP); scenario D1 (recycling to WIB) provided the largest savings. Except for the case of F1, the set of scenarios "WWquality" always provided larger savings than the "WWmix" set, highlighting the benefits of a quality-driven wood waste management versus maximising the quantity sent to recycling. Among the "WWmix" set, scenario A1 (recycling to particleboard with incineration of the recycled product at the end of its lifetime) performed worst because the benefits from substituting virgin particleboard did not counterbalance the burdens from reprocessing; this was 381 due to the low substitution factor (0.6) for the recycled particleboard alongside the relatively low impact of 382 particleboard manufacture from virgin wood relative to that from recycled materials. Impacts associated with 383 biogenic $\mathrm{CO}_{2}$ emissions following incineration of the recycled particleboard at EoL constituted $60 \%$ of burdens. Additional recycling iterations of the particleboard at EoL increased the savings. Scenarios B1-B4 incurred larger savings than the corresponding scenarios A1-A4 (e.g. $-88 \mathrm{~kg} \mathrm{CO}{ }_{2}$ eq/FU in B1 compared with $-11 \mathrm{~kg} \mathrm{CO} 2 \mathrm{eq} / \mathrm{FU}$ in $\mathrm{A} 1$ ), owing to a higher substitution factor for the first iteration of recycled particleboard production, despite the burdens deriving from biogenic $\mathrm{CO}_{2}$ emissions following combustion of the lower

followed by recycling to flooring: the final net savings were $640 \%$ and $446 \%$ larger than for recycling to particleboard (scenarios D1 and C1 compared to B1, respectively). Such net savings appeared much larger quality wood (Q3+Q4; 72\% of burdens). Although subsequent iterations of particleboard production in "WWquality" scenarios were modelled under the same assumptions of scenarios A1-A4, scenarios B1-B4 showed larger savings, still owing to the credits obtained by the first cascade step.

When looking at applications other than particleboard, recycling to WIB showed the best performance when compared to the "WWmix" scenarios: net savings in scenarios D1 and C1 were as much as 58 and 35 times larger compared to scenario A1. This was mainly due to the larger savings obtained from substituting more energy-intensive products such as virgin wood floorings and insulation glass wool alongside recycling to products characterised by a longer lifetime, thereby increasing GWP100 savings thanks to carbon storage. Indeed, material substitution in scenarios D1 and C1 contributed to $66 \%$ and $49 \%$ of savings respectively, following a lifetime of the products estimated at 30 and 50 years, respectively (see Figure 1). On the other hand, recycling to WPC composites (scenario E1), despite having a lifetime equal to WIB (30 years), showed a considerably reduced GWP mitigation compared to scenario D1 (-538\% of net savings) and in the range of 
scenario B2. This was mainly because the production of virgin WPC did not require substantially more energy than the recycling process, thereby indicating that long lifetimes per se do not necessarily ensure large savings. Nevertheless, savings in scenario E1 were larger than the "WWmix" scenarios. Recycling of wood waste into pellets (scenario F1) was the only option with a net burden on GWP, mainly due to biogenic emissions from combustion of the wood (407 $\mathrm{kg} \mathrm{CO}_{2}$-eq) that were not offset by substitution of energy ( $349 \mathrm{~kg} \mathrm{CO}_{2}$-eq). While savings derived from combusting wood appeared significant in previous studies (e.g. Suter et al., 2016), this was however the result of assuming displacement of fossil-based energy and of not considering biogenic $\mathrm{CO}_{2}$ emissions.

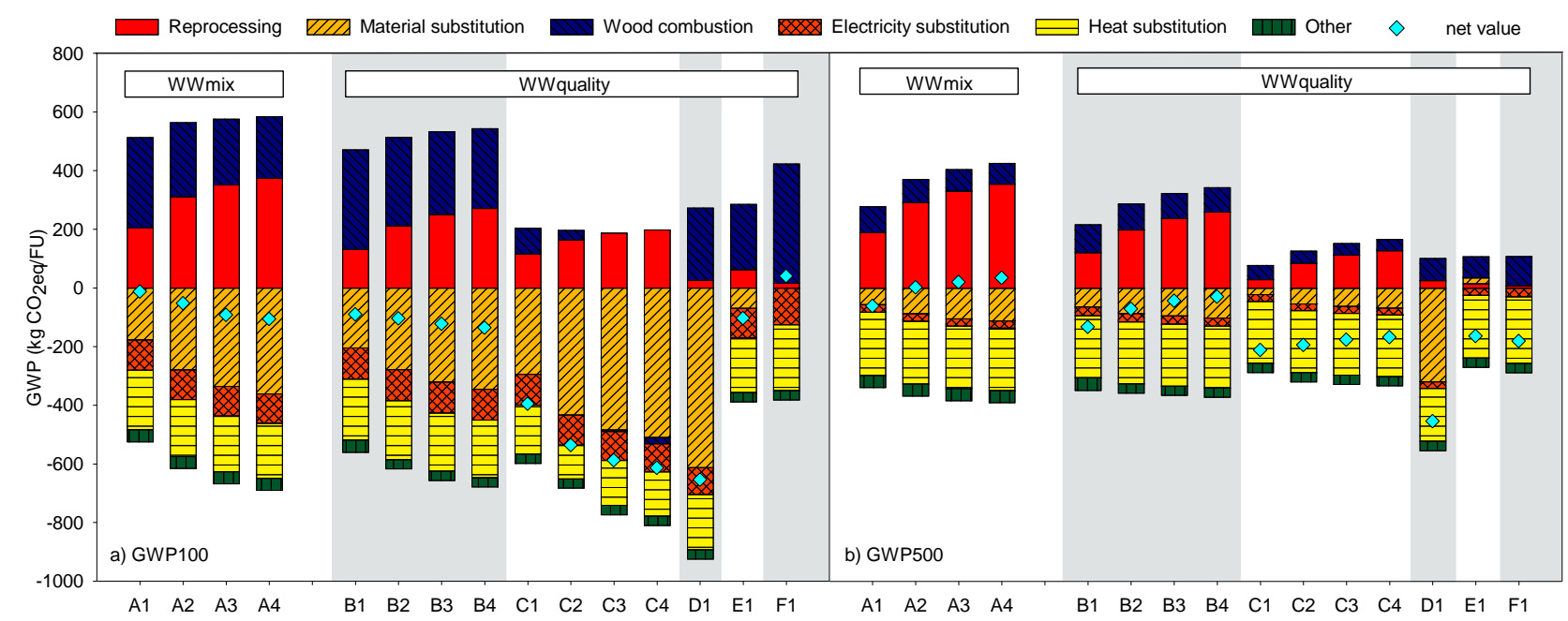

Figure 3. Characterised GWP results for the scenarios under assessment; a) GWP100 and b) GWP500; only $\mathrm{CO}_{2}$ emissions included; rotation time of the wood: $60 \mathrm{y}$; "Other" includes metal recycling and landfill.

\subsection{Cascading effects}

The results showed that within each group of scenarios sharing the same recycling application (i.e. within A1-A4, B1-B4 or C1-C4) the more the cascade steps, the larger the savings obtained: net savings brought by four cascade steps could be more than eight times larger than one-cascade systems (e.g. comparing scenario A4 to A1). However, the incremental savings provided by an additional cascade use declined at each step: from $78 \%$ (A2 compared to A1), to $43 \%$ (A3 to A2), to $15 \%$ (A4 to A3), suggesting an asymptotic trend. 
The reason was that at every cycle half of the mass was lost during particleboard manufacture, owing to a decrease in quality of the feedstock: an indicator of this was that at the third cycle of particleboard recycling (scenarios A3, B3 and C4) 30\% of the mass fed into the recycling process was resin. This means that the activity providing the largest savings in a system occurred at the first cascade step, when the quality of the resource is at its highest point, thereby demonstrating that recycling choices at the early stages of a wood resource's cascade chain are the most important from a GWP perspective. Other studies (Höglmeier et al., 2014; Risse et al., 2017; Suter et al., 2016) demonstrated that savings brought by an additional particleboard cascade in the resource's use can be modest and could even worsen total impacts. However, as mentioned earlier, these studies did not include a dynamic evaluation nor considered impacts from biogenic $\mathrm{CO}_{2}$.

\subsection{Importance of quality}

Comparing "WWmix" against "WWquality" scenarios illustrates that recycling only the upper qualities of wood waste could be beneficial with respect to the GWP performance of the entire system, i.e. the best option in our model was not the one maximising the wood mass sent to recycling but the quality of the resource, despite the burdens from combusting the lower-quality wood (Q3+Q4; Figure 1). For example, in scenarios B1-B4 a combination of incineration and quality-oriented recycling provided larger savings than the corresponding "WWmix" scenarios, despite $651 \mathrm{~kg}$ of wood waste are recycled in scenario B1 compared to the $1000 \mathrm{~kg}$ in scenario A1. In scenario D1, only $42 \%$ of the FU was manufactured into a new product; nevertheless, this scenario showed the best GWP performance. that may generate better environmental performances compared to the case of "WWmix" where particleboard production is the only possible option. Results from Fig. 3 suggested that wood waste recycling should be directed toward applications substituting energy-intensive materials or extending the overall lifetime of the wood resource, as floor boards and WIB appeared to be the case. As Dornburg and Faaij (2005) also demonstrated, one cascade recycling to a high-quality application can result in larger savings than many cascades to a lower-quality application, as is the case in our study for scenarios D1 compared with A1-A4 or 
B1-B4. Additionally, the absence of adhesives in some of the higher-quality recycling applications (in this case floor boards) would in principle allow for larger savings also in other impact categories, since other studies (e.g. Höglemeier et al., 2014; 2015; Suter et al., 2016) demonstrated that the production and use of such chemicals for particleboard making represent the largest contribution in most impact categories.

\subsection{Dynamic accounting and biogenic $\mathrm{CO}_{2}$}

The time dependency of $\mathrm{CO}_{2}$ impacts made results heavily depend on the $\mathrm{TH}$ chosen for the assessment. When a TH of 500 years was selected, the magnitude of the results differed considerably from the GWP100 case: in general, savings decreased by $31-135 \%$ depending on the scenario, except for scenarios A1, B1, E1 and F1, where savings were 1.5-5 times larger (Figure 3b). "WWquality" scenariosprovided savings 2-50 times larger than "WWmix", depending on the scenario. The ranking of scenarios was also affected: for example, additional cascade steps worsened the results (scenarios A1-A4, B1-B4, C1-C4). This reflects the fact that, when considering a GWP assessment over 100 years, most of the savings in the system are related to the biogenic $\mathrm{CO}_{2}$ because of avoiding sourcing of wood for material production and the associated biomass-energy consumption. However, such savings become minor with long THs (e.g. 500 years), as the effect of biogenic carbon storage and emissions tend to fade away and have minor importance (biogenic $\mathrm{CO}_{2}$ savings decreased by $52-89 \%$ depending on the scenario). On the other hand, impacts from fossil $\mathrm{CO}_{2}$ (mainly burdens) are much more prominent. This confirms that biogenic $\mathrm{CO}_{2}$ long-term effects are negligible in comparison to fossil $\mathrm{CO}_{2}$, and emissions from biomass (harvested and re-planted) may be considered carbon-neutral in a very long-time perspective. Results for $\mathrm{TH}=500$ years are indeed in accordance with what found by previous studies that did not consider biogenic $\mathrm{CO}_{2}$ (Höglmeier et al., 2014; Risse et al., 2017; Suter et al., 2016). Scenario F1 changed from being a load onto the environment to being a saving even larger than scenarios C1-C4 (F1 savings increased by 4 times compared to the $\mathrm{TH}=100$-years case). This shows that combustion of biogenic $\mathrm{CO}_{2}$ is indeed beneficial with respect to the indicator GWP when very long timeframes (e.g. 500y) are considered. However, recent publications questioned the usefulness of metrics for TH above 100 years, due to the strong assumption of constant background conditions (Levasseur et al., 2016), thereby challenging the climate 
mitigation potential of biomass-energy. These results indicate that the $\mathrm{TH}$ of the assessment should be carefully selected according to the scope of the study. In LCAs a TH of 100 years is commonly assumed, although the IPCC (2013) states that "there is no scientific argument for selecting 100 years compared to other choices”. Røyne et al. (2016) found that less than 10\% of forest LCAs published in 1997-2013 considered time perspectives other than 100 years. This is supported by the fact that policies and strategies for climate change mitigation generally reflect shorter time perspectives, and by IPCC (2014) thatdiscarded the 500 years case from the list of THs for which providing parameters values. Additional arguments questioning the robustness of very long THs are brought by Reisinger et al. (2010) and Joos et al. (2013) that showed how uncertainties on the IRF for $\mathrm{CO}_{2}$ increase with increasing time horizon. All in all, our choice of assessing also a $\mathrm{TH}$ of 500y follows the recommendations from Cherubini et al. (2016b) and Levasseur et al. (2016) to provide results for various time horizons. As in our study a 20-year-TH was too low due to the typically longer lifetime of the wood products investigated, a TH of 500 years was instead chosen to illustrate the time dependency on the GWP results. .

\subsection{Uncertainty, sensitivity and scenario analysis}

\subsubsection{Combined uncertainty and sensitivity analysis}

The propagation of input uncertainty widened the results for all scenarios, and the obtained score range overlapped for scenarios A1-A4, B1-B4 and E1 (Figure 4). Therefore, it should be considered for decisionmaking that the ranking of scenarios could vary and increased effort should be put into obtaining data tailored to the scope. However, conclusions on scenarios C1-C4, D1 and F1 (i.e. those providing the largest and smallest savings) appeared robust. The uncertainties of the results did not increase with increasing number of cascades, but rather appeared constant throughout the cascading system. This was because, despite another "layer" of uncertainty is added by including an additional cascade step, the mass of the material involved in the extra steps decreases (or even halves). Table H.1 in Appendix H shows the results of the perturbation analysis. For all scenarios covering the material use of wood waste the most sensitive parameter was the technical substitution factor of the recycled product manufactured in the first cascade system, irrespective of 
the number of cascades considered in the system. Energy conversion efficiencies at power plants also played an important role, and were clearly the most important parameters for scenario F1. The model appeared less sensitive to parameters related to energy consumption in the material manufacture process.

\subsubsection{Scenario analysis I - Testing assumptions on electricity system}

Figure 4 illustrates how characterised results changed as a consequence of different scenario analyses. When a fossil fuel-based electricity mix was assumed significantly larger savings were observed for all scenarios compared to the electricity mix (wind and wood) assumed in the baseline, regardless of the time horizon. This was a consequence of the very large savings provided by incineration when the recovered electricity replaced coal, oil and gas. The "WWquality" scenarios still performed better than the "WWmix" in all cases. The ranking of scenarios did alter: scenario F1 (pellets-CHP) changed from being a net load onto the environment to providing larger savings than scenarios A1-A4, B1-B4 and E1. Additional cascade steps resulted in lower total savings (e.g. scenarios A2-A4 compared to A1); the decrease in incremental savings given by additional cascades was confirmed and with a more or less steep trend depending on the TH. Under this assumption for electricity mix, the timing of emissions had a negligible effect on the results, which appeared to be driven by savings from avoided electricity production only. This indicates that the energy use of wood may be favourable when displacing fossil fuel-based energy. Yet, this is unlikely to be the future marginal electricity source in Denmark or the EU, given the commitment to ambitious renewable energy targets. 


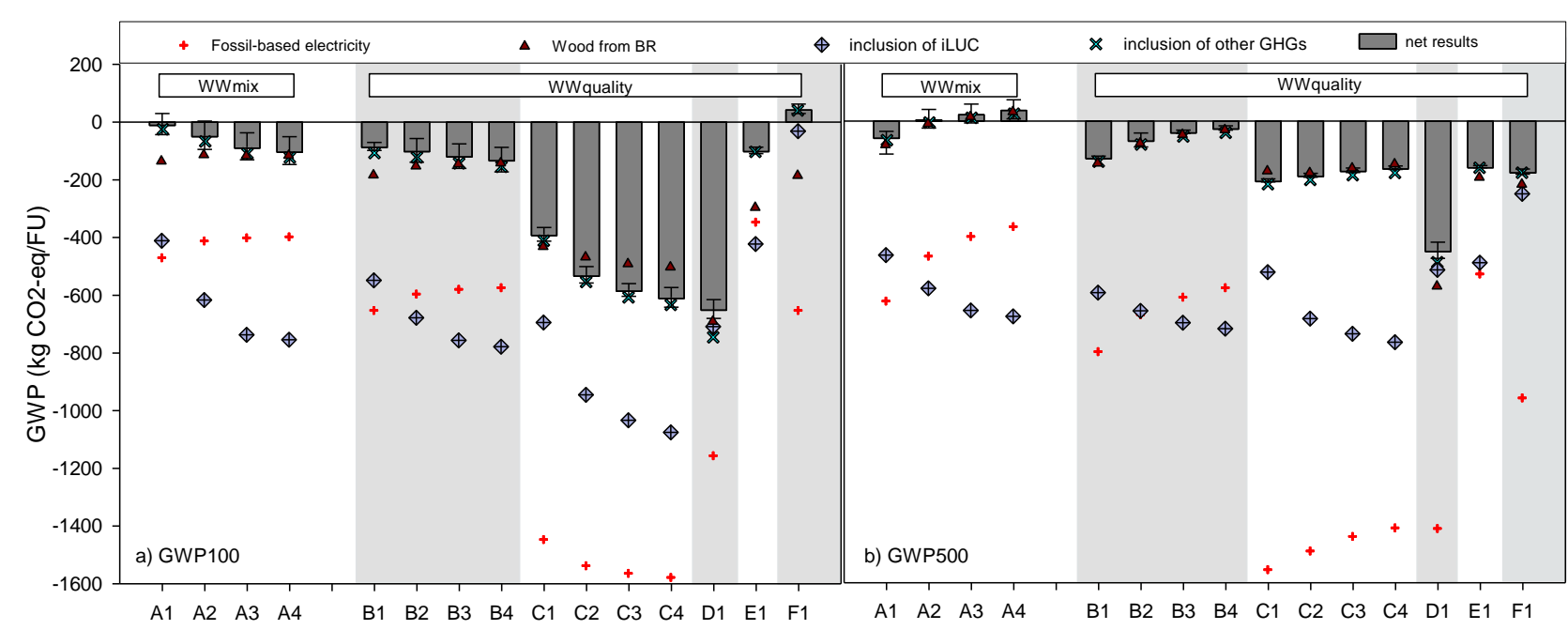

520 Fig 4. Global Warming Potential results for $\mathrm{TH}=100$ years (a) and $\mathrm{TH}=500$ years (b) under baseline 521 conditions (only $\mathrm{CO}_{2}$ emissions included; grey vertical bars, error bars represent the min and max value 522 obtained by uncertainty propagation; rotation time of the wood 60y), fossil-based electricity provision (redcross mark), sourcing of wood from Brazil (dark-red triangular mark), inclusion of other GHGs (cyantriangular mark), inclusion of iLUC (crossed-lilac diamond mark; assuming a rotation time of the wood of $60 y)$. Refer to Figure 1 for definition of scenarios.

\subsubsection{Scenario analysis II - Inclusion of iLUC and other GHGs}

The inclusion of iLUC greatly affected the results for most of the assessed scenarios (Figure 4), incurring considerably larger savings. The contribution of iLUC generally accounted for 38-48\% of savings for TH=100 years and 52-64\% for $\mathrm{TH}=500$ years. This is in line with the figures reported in Hoeglemeier et al. (2014) for land transformation, thereby suggesting that the substitution of energy-intensive products does not ensure the highest savings when compared to substitution of land-intensive products (scenario D1 ranked second-to-last when iLUC effects are included). These results should be used cautiously as only illustrative of the potential iLUC contribution under the assumption of sourcing wood from long-rotation forests (baseline used in this study; rotation 60 years); the iLUC factor for wood derived from short-rotation plantations would be significantly lower, e.g. $0.05 \mathrm{~kg} \mathrm{CO}_{2} / \mathrm{kg}$ wood from Brazilian eucalyptus (Schmidt and Brandao, 2012; Tonini et al., 2017), thereby decreasing the overall iLUC contribution by $70 \%$ compared to the value shown in Figure 4 for the baseline wood source(see Figure G.2 in Appendix G). 
The inclusion of other GHGs changed neither the ranking nor the order of magnitude of the results.

540 However, their contribution to the total scenario impact differed among scenarios: while in "WWquality" 541 scenarios their contribution was relatively small (1-18\% of net savings with TH=100 years), in "WWmix" 542 scenarios it accounted for up to 55\% (scenario A1), mainly originating from a larger production of resin in 543 particleboard manufacturing for a larger fraction of the FU (100\%) compared to scenario B1 (60\%, since only $544 \mathrm{Q} 1+\mathrm{Q} 2$ are recycled). The contribution from other GHGs decreased to about half when selecting $\mathrm{TH}=500$ 545 years, and appeared to decrease with increasing number of cascade steps in the system.

\subsubsection{Scenario analysis II - Testing assumptions on wood sourcing and rotation}

In the scenario where wood was imported from Brazilian short-plantation eucalyptus (rotation time: 10 years), the benefits on GWP100 increased compared to the baseline results (where wood had a rotation time of 60y), especially for short-life cascades (i.e. A1-A2, B1-B2, D1, E1, F1) while these were less prominent for longer-life cascades (i.e. A3-A4, B3-B4, C1) and finally decreased for scenarios C2-C4 (see also Figure G.1 in Appendix G). The reason behind is that shorter rotation plantations sequester carbon more rapidly than temperate forests, with visible savings in the short term; however, the sequestration process terminates earlier than for temperate forests, which continue sequestering carbon and provide larger overall savings if the wooden product has a longer lifetime. The results for GWP500 were very similar to the baseline, underlining once again that the GWP effects of biogenic emissions are minor over long timeframes. The additional analysis performed by varying the biomass rotation period affected the results differently depending on the number of cascades. In Figure 5 activity emissions were aggregated according to the use cycle at which they occurred to 559 highlight the role of each cascade step in the assessed scenarios. In general, the shorter the rotation of the wood, the larger the net savings, because the new plantation can re-sequester emitted $\mathrm{CO}_{2}$ faster. However, while net savings for one-cascade systems decreased (and became burdens) with longer biomass rotations, net 

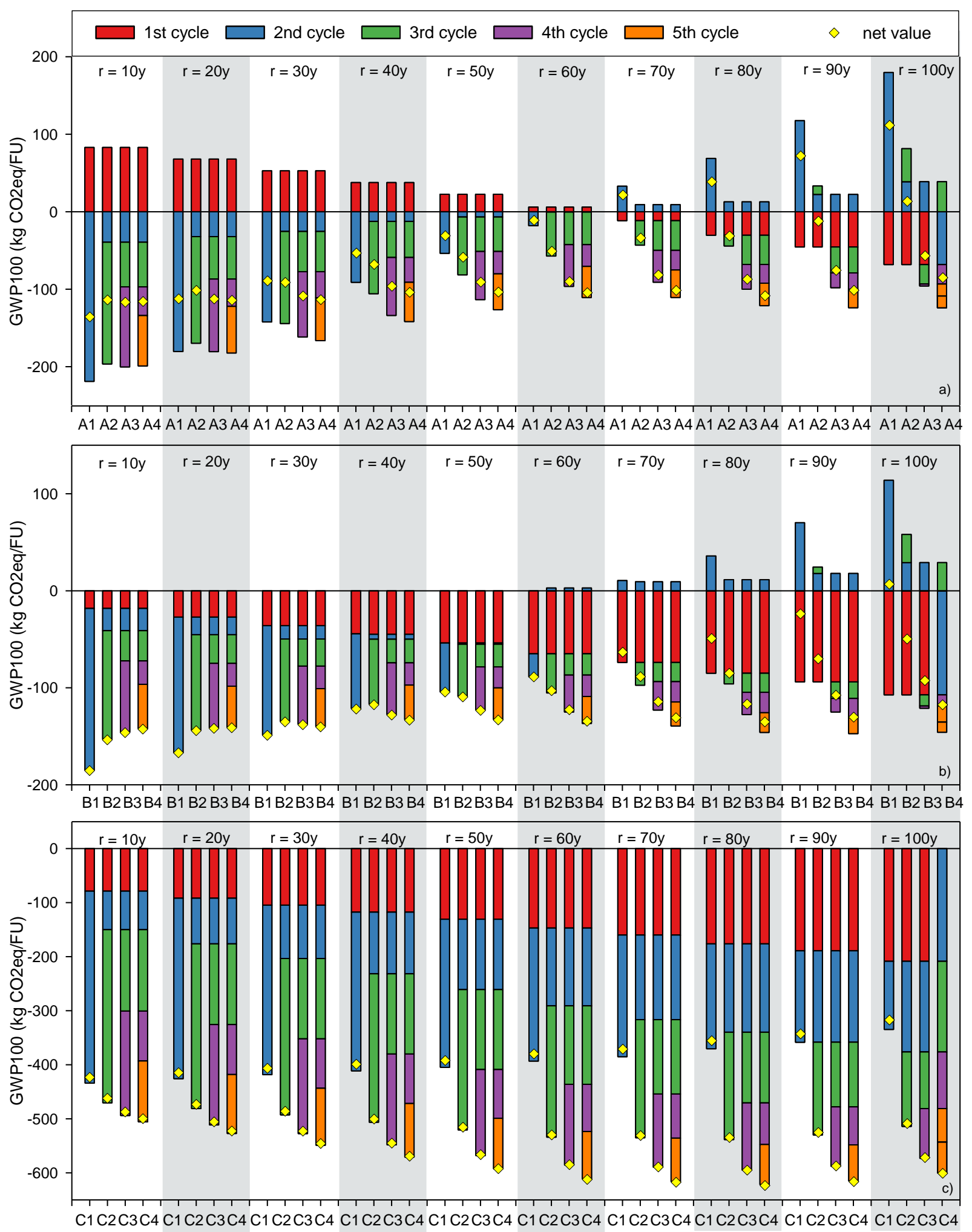

565 Figure 5. Global Warming Potential results ( $\mathrm{TH}=100$ years) for varying sources (i.e. rotations, $\mathrm{r}$ ) of the wood 566 biomass under study in scenarios a) A1-A4, b) B1-B4 and c) C1-C4. Activity emissions are aggregated 567 according to the use cycle at which they occurred. The numbers of cycles $\left(1^{\text {st }}, 2^{\text {nd }}\right.$, etc. $)$ do not correspond to 
the emission year $(0,10,20$, etc.), which conversely depends on the scenario under assessment (please refer to Figure 1, also for the definition of scenarios).

\subsection{Implications and limitations of the study}

The study focused on the evaluation of wood management systems from a climate change point of view only. However, recycling and incineration of wood waste may provide environmental savings/impacts in other impact categories. For example, the type of wood species may influence not only the GWP results, but also the biodiversity loss when fast-growing species are grown in place of longer rotation forests, as it is anticipated to occur in Brazil (see Thrän et al., 2017). Also, it is reported that incineration of particleboard releases higher levels of dioxins than solid wood (Gao et al., 2017), thereby potentially contributing to ecotoxicity and human toxicity impacts. This may be an incipient issue to tackle, as the more cascades to particleboard, the higher the concentration of resin in the recycled products, and potentially the higher the emissions when the product is incinerated at the end of its lifetime.

The consequential approach adopted in this study was based on two fundamental assumptions: the first is the long-term full-elasticity of supply, i.e. possible short-term effects due to fluctuations in prices of goods are not included (Weidema et al., 2009). This is especially the case for the iLUC factors used in our analysis (Schmidt et al., 2015; see section 2.6.4). Other studies applying economic modelling and considering shortterm effects following price fluctuations argue that decreasing demand for virgin wood for material/energy production may decrease the price of forest timber which could potentially increase demand for other wood products, thus ultimately leaving the amount of forest-land unchanged (Plevin, 2016; Valin et al., 2015). Yet, this is unlikely for long-rotation forests where forest owners may decide to delay harvest if prices for timber are too low (Valin et al., 2015). This once again stresses the importance of both including iLUC effects and also finding a consensus on the methodology, although this goes far beyond the aim of this study. The second assumption regards the scale of the effects induced by the change in waste management, assumed here to be small (or negligible), i.e. not affecting the demand/market volume and the constraints on and production costs of the involved products/technologies (Weidema et al., 2009). We infer this assumption to be fair considering 
that the current wood waste potential is minor compared to the wood supply market (Section 2.1); nevertheless, complementary analyses could be performed in support of policy proposals.

The focus of the study was on Danish wood. Although the results from the scenario analysis on the electricity system (Section 3.5.1) showed that country-specific background conditions may alter the magnitude of the results, the environmentally sound conclusions on quality separation of wood waste at the collection phase were robust even under different electricity mixes or considering iLUC, all in all suggesting that results can be extended to other contexts. Management systems should be configured as to separately collect wood waste qualities; this may, in addition to saving $\mathrm{CO}_{2}$, reduce competition of uses between energy and material sector. This would hold true especially in the case of countries with a growing economy, where resource cascading is an arising subject. Finally, we would like to stress that a dynamic assessment of GWP impacts (including biogenic $\mathrm{CO}_{2}$ ) should be implemented whenever addressing long-time systems of bio-based products, for example when quantifying the carbon footprint of wood-based buildings or in the use of bioplastics.

\section{Conclusions}

Drawing upon the comparison of 15 alternative wood waste cascading management scenarios, we showed from a climate change mitigation perspective - that quality-oriented recycling is preferred to maximizing the quantity sent to recycling. Assuming a time horizon for the Global Warming Potential assessment of 100 years, the benefits appeared larger when: i) increasing the number of cascade steps in the system, ii) the recycling application had a long life-time, and iii) the recycling application substituted energy-intensive materials. The latter, though, is only true when potential indirect land use change effects are excluded: their inclusion makes substitution of land-intensive products preferable. Other sensitive assumptions were the choice of the time horizon, the electricity system and the rotation time of the wood biomass: for longer time horizons, fossil fuelbased electricity systems or short-rotation plantations (as marginal source of wood), shorter cascade systems appeared preferable to longer cascade chains. Including other GHGs negligibly affected the results. Performing a dynamic GHG emissions accounting is key to capturing the effects of biogenic $\mathrm{CO}_{2}$ and storage, e.g. for 
620 long-lifetime products; however, the results heavily depend on the time horizon chosen for the Global 621 Warming Potential assessment.

\section{Disclaimer}

624 The views expressed in the article are the sole responsibility of the authors and in no way represent the view 625 of the European Commission and its services.

626

\section{Acknowledgments}

628 The Danish Environmental Protection Agency is highly appreciated for funding this study. The authors are 629 also grateful to Francesco Cherubini (Norwegian University of Science and Technology) and Jacopo Giuntoli 630 (International Council on Clean Transportation) for useful comments on the study.

\section{$632 \quad$ Funding}

633 This work was supported by the Danish Environmental Protection Agency (Miljøstyrelsen).

Altholz V (2012) Verordnung über Anforderungen an die Verwertung und Beseitigung von Altholz (Altholzverordnung - AltholzV). The German waste wood ordinance.

Bais-Moleman, A.L., Sikkema, R., Vis, M., Reumerman, P., Theurl, M.C., Erb, K.H., 2018. Assessing wood use efficiency and greenhouse gas emissions of wood product cascading in the European Union. J. Clean. Prod. 172, 3942-3954. https://doi.org/10.1016/j.jclepro.2017.04.153 
644 Bisinella, V., Astrup, T.F., Højlund, T., 2017. Future scenario development within life cycle assessment of waste management systems. Technical University of Denmark.

Bolin, C.A., Smith, S., 2011. Life cycle assessment of ACQ-treated lumber with comparison to wood plastic composite decking. J. Clean. Prod. 19, 620-629. https://doi.org/10.1016/j.jclepro.2010.12.004

Börjesson, P., Gustavsson, L., 2000. Greenhouse gas balances in building construction : wood versus concrete from life-cycle and forest land-use perspectives. Energy Policy 28, 575-588.

Cherubini, F., Peters, G.P., Berntsen, T., Strømman, A.H., Hertwich, E., 2011. CO2 emissions from biomass combustion for bioenergy: atmospheric decay and contribution to global warming. GCB Bioenergy 3, 413-426. https://doi.org/10.1111/j.1757-1707.2011.01102.x

Cherubini, F., Bright, R.M., Strømman, A.H., 2013. Global climate impacts of forest bioenergy: what , when and how to measure ? Environ. Res. Lett. 8. https://doi.org/10.1088/1748-9326/8/2/029503

Cherubini, F., Huijbregts, M., Kindermann, G., Van Zelm, R., Van Der Velde, M., Stadler, K., Strømman, A.H., 2016. Global spatially explicit CO2emission metrics for forest bioenergy. Sci. Rep. 6, 1-12. https://doi.org/10.1038/srep20186

Cherubini, F., Fuglestvedt, J., Gasser, T., Reisinger, A., Cavalett, O., Huijbregts, M.A.J., Johansson, D.J.A., Jørgensen, S. V., Raugei, M., Schivley, G., Strømman, A.H., Tanaka, K., Levasseur, A., $2016 b$. Bridging the gap between impact assessment methods and climate science. Environ. Sci. Policy 64, 129-140. https://doi.org/10.1016/j.envsci.2016.06.019

Clavreul, J., Baumeister, H., Christensen, T.H., Damgaard, A., 2014. An environmental assessment system for environmental technologies. Environ. Model. Softw. 60, 18-30. https://doi.org/10.1016/j.envsoft.2014.06.007 
665 De Rosa, M., 2017. How methodological choices affect LCA climate impact results: the case of structural timber. Int. J. Life Cycle Assess. https://doi.org/10.1007/s11367-017-1312-0

Dodoo, A., Gustavsson, L., Sathre, R., 2009. Carbon implications of end-of-life management of building materials. Resour. Conserv. Recycl. 53, 276-286. https://doi.org/10.1016/j.resconrec.2008.12.007

Dornburg, V., Faaij, A.P.C., 2005. Cost and $\mathrm{CO}_{2}$-emission reduction of biomass cascading: Methodological aspects and case study of SRF poplar. Clim. Change 71, 373-408. https://doi.org/10.1007/s10584-005$5934-\mathrm{z}$

EC (European Commission), 2016a. Commission staff working document. Impact Assessment. Sustainability of Bioenergy. Accompanying the document: Proposal for a Directive of the European Parliament and of the Council on the promotion of the use of energy from renewable sources (recast). https://eur-lex.europa.eu/resource.html?uri=cellar:1bdc63bd-b7e9-11e6-9e3c$\underline{01 \mathrm{aa} 75 \mathrm{ed} 71 \mathrm{a} 1.0001 .02 / \mathrm{DOC} \_1 \& \text { format }=\mathrm{PDF}}$

EC (European Commission), 2016b. EU reference scenario 2016. Energy, transport and GHG emissions Trends to 2050. https://ec.europa.eu/energy/en/content/2013-\%E2\%80\%93-eu-energy-transport-andgreenhouse-gas-emissions-trends-2050

FAO/UNECE (2016). Forest Products. Annual market overview 2015-2016. Geneva, October 2016. ISBN: 978-92-1-117115-0

Faraca, G., Boldrin, A., Damgaard, A., Astrup, T.F., 2017. Challenges to a circular economy - the presence of impurities in wood waste for recycling. Proceedings Sardinia 2017.

Forster, P., et al., 2007: Changes in atmospheric constituents and in radiative forcing. In: Climate Change 2007: The Physical Science Basis. Contribution of Working Group I to the Fourth Assessment Report of the Intergovernmental Panel on Climate Change [Solomon, S., D. Qin, M. Manning, Z. Chen, M. 
Marquis, K. B. Averyt, M. Tignor and H. L. Miller (eds.)]. Cambridge University Press, Cambridge, United Kingdom and New York, NY, USA, 131-234.

Fraanje, P.J., 1997. Cascading of pine wood. Resour. Conserv. Recycl. 19, 21-28. https://doi.org/10.1016/S0921-3449(96)01159-7

González-García, S., Feijoo, G., Widsten, P., Kandelbauer, A., Zikulnig-Rusch, E., Moreira, M.T., 2009. Environmental performance assessment of hardboard manufacture. Int. J. Life Cycle Assess. 14, 456466. https://doi.org/10.1007/s11367-009-0099-z

Guest, G., Cherubini, F., Strømman, A.H., 2012. Global Warming Potential of Carbon Dioxide Emissions from Biomass Stored in the Anthroposphere and Used for Bioenergy at End of Life 17. https://doi.org/10.1111/j.1530-9290.2012.00507.x

Gurria, P., Ronzon, T., Tamosiunas, S., Lopez, R., Garcia Condado, S., Guillen, J., ... M’Barek, R., 2017. Biomass flows in the European Union: The Sankey biomass diagram - Towards a crossset integration of biomass. Joint Research Center, Seville. https://doi.org/10.2760/352412

Höglmeier, K., Weber-Blaschke, G., Richter, K., 2014. Utilization of recovered wood in cascades versus utilization of primary wood-a comparison with life cycle assessment using system expansion. Int. J. Life Cycle Assess. 1755-1766. https://doi.org/10.1007/s11367-014-0774-6

Höglmeier, K., Steubing, B., Weber-Blaschke, G., Richter, K., 2015. LCA-based optimization of wood utilization under special consideration of a cascading use of wood. J. Environ. Manage. 152, 158-170. https://doi.org/10.1016/j.jenvman.2015.01.018

Intergovernmental Panel on Climate Change (IPCC), 2013. Climate Change 2013. The physical science basis. Working group I contribution to the fifth assessment report of the intergovernmental panel on climate change. (Stocker, T.F., D. Qin, G.-K. Plattner, M. Tignor, S.K. Allen, J. Boschung, A. Nauels, 

Y. Xia, V. Bex and P.M. Midgley (eds.)). Cambridge University Press, Cambridge, United Kingdom and New York, NY, USA, $1535 \mathrm{pp}$.

Intergovernmental Panel on Climate Change (IPCC), 2014. In: Pachauri, R.K., Meyer, L.A. (Eds.), Climate Change 2014: Synthesis Report. Contribution of Working Groups I, II and III to the Fifth Assessment Report of the Intergovernmental Panel on Climate Change. Geneva.

ISO 14040, 2006. Environmental Management-Life Cycle Assessment-Principles and Framework, second ed. ISO, Geneva, Switzerland.

Joos, F., et al., 2013: Carbon dioxide and climate impulse response functions for the computation of greenhouse gas metrics: A multi-model analysis. Atmos. Chem. Phys., 13, 2793-2825.

Kalt, G., Höher, M., Lauk, C., Schipfer, F., Kranzl, L., 2016. Carbon accounting of material substitution with biomass: Case studies for Austria investigated with IPCC default and alternative approaches. Environ. Sci. Policy 64, 155-163. https://doi.org/10.1016/j.envsci.2016.06.022

Krook, J., Eklund, M., 2010. The strategic role of recycling centres for environmental performance of waste management systems. Appl. Ergon. 41, 362-367. https://doi.org/10.1016/j.apergo.2009.06.012

Leek, N., 2010. Post-consumer wood. Pp 93-96. In : EUwood - Final report. Hamburg (Germany), 160 pp.

Levasseur, A., Lesage, P., Margni, M., Deschěnes, L., Samson, R., 2010. Considering time in LCA: Dynamic LCA and its application to global warming impact assessments. Environ. Sci. Technol. 44, 3169-3174. https://doi.org/10.1021/es9030003

Levasseur, A., Lesage, P., Margni, M., Samson, R., 2013. Biogenic Carbon and Temporary Storage Addressed with Dynamic Life Cycle Assessment. J. Ind. Ecol. 17, 117-128. https://doi.org/10.1111/j.1530-9290.2012.00503.x 
Bais-Moleman, A.L., Sikkema, R., Vis, M., Reumerman, P., Theurl, M.C., Erb, K.H., 2018. Assessing wood use efficiency and greenhouse gas emissions of wood product cascading in the European Union. J. Clean. Prod. 172, 3942-3954. https://doi.org/10.1016/j.jclepro.2017.04.153

Mantau, U., Saal, U., Prins, K., Steierer, F., Lindner, M., Verkerk, H., Eggers, J., Leek, N., Oldenburger, J., Asikainen, A., Anttila, P., 2010. EUwood - Real potential for changes in growth and use of EU forests. Final report. EUwood 106p. https://doi.org/TREN/D2/491-2008

Mehr, J., Vadenbo, C., Steubing, B., Hellweg, S., 2018. Environmentally optimal wood use in SwitzerlandInvestigating the relevance of material cascades. Resour. Conserv. Recycl. 131, 181-191. https://doi.org/10.1016/j.resconrec.2017.12.026

Merrild, H., Christensen, T.H., 2009. Recycling of wood for particle board production: accounting of greenhouse gases and global warming contributions. Waste Manag. Res. 27, 781-788. https://doi.org/10.1177/0734242X09349418

Morris, J., 1996. Recycling versus incineration: an energy conservation analysis. J. Hazard. Mater. 47, $277-$ 193.

Muñoz, I., Schmidt, J.H., De Saxcé, M., Dalgaard, R., Merciai, S., 2015. Inventory of country specific electricity in LCA - consequential scenarios. Version 3.0. Report of the 2.-0 LCA Energy Club. 2.-0 LCA consultants, Aalborg http://lca-net.com/clubs/energy/

Plevin, R.J., 2016. Assessing the climate effects of biofuels using integrated assessment models, part I. J. Ind. Eco. 21(6), 1478-1487. doi: epdf/10.1111/jiec.12507

Reisinger, A., Meinshausen, M., Manning, M., Bodeker, G., 2010. Uncertainties of global warming metrics : CO 2 and CH 4. Geophys. Res. Lett. 37, 2-7. https://doi.org/10.1029/2010GL043803 
Risse, M., Weber-Blaschke, G., Richter, K., 2017. Resource efficiency of multifunctional wood cascade chains using LCA and exergy analysis, exemplified by a case study for Germany. Resour. Conserv. Recycl. 126, 141-152. https://doi.org/10.1016/j.resconrec.2017.07.045

Rivela, B., Moreira, M.T., Muñoz, I., Rieradevall, J., Feijoo, G., 2006a. Life cycle assessment of wood wastes: A case study of ephemeral architecture. Sci. Total Environ. 357, 1-11. https://doi.org/10.1016/j.scitotenv.2005.04.017

Rivela, B., Hospido, A., Moreira, T., Feijoo, G., 2006b. Life Cycle Inventory of Particleboard: A Case Study in the Wood Sector. Int. J. Life Cycle Assess. 11, 106-113. https://doi.org/10.1065/lca2005.05.206

Røyne, F., Peñaloza, D., Sandin, G., Berlin, J., Svanström, M., 2016. Climate impact assessment in life cycle assessments of forest products : implications of method choice for results and decision- making 116, 90-99. https://doi.org/10.1016/j.jclepro.2016.01.009

Schmidt, J.H., Brandão, M., 2013. LCA screening of biofuels - iLUC, biomass manipulation and soil carbon. Aalborg.

Schmidt, J.H., Weidema, B.P., Brandão, M., 2015. A framework for modelling indirect land use changes in Life Cycle Assessment. J. Clean. Prod. 99, 230-238. https://doi.org/10.1016/j.jclepro.2015.03.013

Sikkema, R., Junginger, M., McFarlane, P., Faaij, A., 2013. The GHG contribution of the cascaded use of harvested wood products in comparison with the use of wood for energy-A case study on available forest resources in Canada. Environ. Sci. Policy 31, 96-108. https://doi.org/10.1016/j.envsci.2013.03.007

Sirkin, T., Houten, M., 1994. The cascade chain. A theory and tool for achieving resource sustainability with applications for product design. Resour. Conserv. Recycl. 10, 213-276. https://doi.org/10.1016/09213449(94)90016-7 
Sommerhuber, P.F., Wenker, J.L., Rüter, S., Krause, A., 2017. Life cycle assessment of wood-plastic composites: Analysing alternative materials and identifying an environmental sound end-of-life option. Resour. Conserv. Recycl. 117, 235-248. https://doi.org/10.1016/j.resconrec.2016.10.012

Steico, 2016. Environmental product declaration of wood fibre insulation materials. declaration number EPD-STE-20150327-IBD1-EN. Available at: http://www.steico.com/fileadmin/steico/content/pdf/Certificates__Documents/English_multiple_markets_/STEICO_EPD-STE-20150327-IBD1-EN.pdf

Suter, F., Steubing, B., Hellweg, S., 2016. Life Cycle Impacts and Benefits of Wood along the Value Chain: The Case of Switzerland. J. Ind. Ecol. 00, 1-13. https://doi.org/10.1111/jiec.12486

Thonemann, N., Schumann, M., 2018. Environmental impacts of wood-based products under consideration of cascade utilization: A systematic literature review. J. Clean. Prod. 172, 4181-4188. https://doi.org/10.1016/j.jclepro.2016.12.069

Thrän, D., Peetz, D., Schaubach, K., 2017. Global Wood Pellet Industry and Trade Study 2017. IEA Bioenergy Task 40. June 2017

Tonini, D., Vadenbo, C., Fruergaard, T., 2017. Priority of domestic biomass resources for energy: Importance of national environmental targets in a climate perspective. Energy 124, 295-309. https://doi.org/10.1016/j.energy.2017.02.037

Vadenbo, C., Tonini, D., Astrup, T.F., 2017. Environmental Multiobjective Optimization of the Use of Biomass Resources for Energy. https://doi.org/10.1021/acs.est.6b06480

Valin, H., Peters, D., van den Berg, M., ... Di Fulvio, F., 2015. The land use change impact of biofuels consumed in the EU - Quantification of area and greenhouse gas impacts. Project number: BIENL13120. Final report for the European Commission. Available at: https://ec.europa.eu/energy/sites/ener/files/documents/Final\%20Report_GLOBIOM_publication.pdfs 
Vis M., U. Mantau, B. Allen (Eds.), 2016. Study on the optimised cascading use of wood. No 394/PP/ENT/RCH/14/7689. Final report. Brussels 2016. 337 pp

798 Weidema, B., Ekvall, T., Heijungs, R., 2009. Guidelines for application of deepened and broadened LCA. Deliverable D18 of work package 5 of the CALCAS project. Enea, IT.

800 Werner F, Taverna R, Hofer P, Thürig E, Kaufmann E., 2010. National and global greenhouse gas dynamics 801 802 of different forest management and wood use scenarios: a model-based assessment. Environ Sci Policy 13(1):72-85.

803 Wilson, J., 2010. Life-cycle inventory of particleboard in terms of resources, emissions, energy and carbon. 804 Wood Fiber Sci. 42, 107-124.

805 